\title{
Small Intestinal Mucosa-Associated Lymphoid Tissue Lymphoma
}

National Cancer Institute

\section{Source}

National Cancer Institute. Small Intestinal Mucosa-Associated Lymphoid Tissue

Lymphoma. NCl Thesaurus. Code C5635.

A mucosa-associated lymphoid tissue lymphoma (MALT) that arises from the small intestine. The morphologic characteristics are similar to those seen in gastric MALT lymphomas, with the exception of the lymphoepithelial lesions that are less prominent in the small intestine. 